\title{
Biomarkers for gastric cancer: molecular classification revisited
}

\author{
Jeeyun Lee ${ }^{1}$, Kyoung-Mee Kim² \\ ${ }^{1}$ Division of Hematology-Oncology, Department of Medicine, Samsung Medical Center, Sungkyunkwan University School of \\ Medicine, Seoul, Korea \\ ${ }^{2}$ Department of Pathology and Translational Genomics, Samsung Medical Center, Sungkyunkwan University School of Medicine, \\ Seoul, Korea
}

Received: February 7, 2017

Revised: June 13, 2017

Accepted: June 16, 2017

Corresponding author:

Kyoung-Mee Kim

Department of Pathology and

Translational Genomics, Samsung

Medical Center, Sungkyunkwan

University School of Medicine,

81 Irwon-ro, Gangnam-gu, Seoul

06351, Korea

Tel: +82-2-3410-2768

E-mail:kkmkys@skku.edu

\begin{abstract}
Gastric cancer (GC) is one of the most common lethal cancer worldwide. In recent years, several new targeted therapeutic agents for the treatment of metastatic GC have been developed. These include drugs that block human epidermal growth factor receptor 2 (HER2) or epidermal growth factor receptor, ramucirumab monoclonal antibody that binds to a receptor for vascular endothelial growth factor, and other targeted agents such as sorafenib and apatinib, and immunotherapies. In this short review, we provide a summary of clinical and preclinical biomarkers (HER2, mesenchymal-epithelial transition [MET], fibroblast growth factor receptor 2 [FGFR2], ring finger protein 43 [RNF43], microsatellite instability and mismatch repair, Epstein-Barr virus, programmed cell death ligand-1, and tumor infiltrating lymphocytes) for treatment strategies and will address the molecular classification of GC revisited with an aim to select the best-precision treatment strategies for $\mathrm{GC}$ patients.
\end{abstract}

Keywords: Biomarkers; Neoplasms; Precision; Stomach; Therapeutics
This is an Open Access article distributed under the terms of the Creative Commons Attribution Non-Commercial License (http:// creativecommons.org/licenses/ by-nc/4.0/).

\section{INTRODUCTION}

The American Cancer Society's estimates for stomach cancer in the United States for 2017 are about 28,000 cases of gastric cancer (GC) will be diagnosed (17,750 in men and 10,250 in women) and about 10,960 people will die from this cancer (6,720 men and 4,240 women) (https:// www.cancer.org). Stomach cancer is much more common in other parts of the world including Korea, China, and Japan. In patients diagnosed with advanced GC disease stage, the patients have a dismal prognosis with a high mortality rate.

Chemotherapy target cells that divide rapidly; however, there are other aspects of cancer cells that make them different from normal cells and many researchers have developed new drugs targeting those differences. As a result of the rapid advancements in the field of tumor biology, attention has been focused on the new modality of molecular targeted therapy for advanced cancer [1]. Therefore, targeted drugs may work in some cases when standard chemotherapy does not work with fewer side effects than standard chemotherapy. 
Molecular targeted inhibitors effectively regulate overexpressed molecules in tumor cells and the signaling pathways that are closely associated with tumorigenesis; thereby, modulating the biological behavior of tumor cells [2]. The genomic landscape of GC is highly heterogeneous [3]. Therefore, it is difficult to target the entire tumor because subclones of GC cells exhibit different biological behaviors. To date, only two targeted treatments, trastuzumab, and ramucirumab, have become part of the treatment paradigm for GC, partly due to difficulties in defining predictive biomarkers in this disease [4]. There are many promising drugs in the pipeline and this article will describe the targets (biomarkers) associated with GC treatment and other potential novel approaches targeting DNA repair deficiencies and the immune system and will include human epidermal growth factor receptor 2 (HER2), mesenchymal-epithelial transition (MET), fibroblast growth factor receptor 2 (FGFR2), ring finger protein 43 (RNF43), microsatellite instability (MSI), mismatch repair (MMR), Epstein-Barr virus (EBV), programmed cell death ligand-1 (PDL1), and tumor infiltrating lymphocytes (TILs).

\section{HER2}

\section{HER2 immunohistochemistry in gastric cancer: what} is different from the breast HER2?

HER2 protein overexpression and gene amplification are more heterogeneous in GC and require a different immunohistochemistry (IHC) scoring system compared to breast cancer (HER2 testing in GC: recommendations of an Asia-Pacific Task Force). Heterogeneous staining is a true biological feature that is far more common in gastric and gastroesophageal junction carcinomas than in breast carcinomas [5] and is estimated to be present in up to $30 \%$ of HER2-positive GC cases. Heterogeneous HER2 overexpression was observed in 33\% of HER2-positive GC cases using quadruplicated tissue microarray study. Discrepancy was also observed in $20 \%$ of paired primary and distant metastases in HER2-positive GC cases [6]. These results suggest that intratumoral heterogeneity and discrepant HER2 results in primary and metastatic tumor are not uncommon in GC. Heterogeneity is more often detected in IHC 2+ cases or in mixed histologic type by Lauren often associated with chromosome 17 polysomy ( $\geq 3$ CEP17 [chromosome enumeration probe 17] signals per nuclei) (Fig. 1) [7].

\section{Factors affecting gastric HER2 positivity and how can we overcome}

The overall frequency of HER2 overexpression in GC ranged from $7 \%$ to $53.4 \%$ with a mean of $17.9 \%$ [6]. This wide range of overexpression of HER2 might be explained by location within the stomach (higher in upper third compared to lower stomach), histologic subtype (34\% in intestinal subtype compared to $6 \%$ in diffuse-type), disease stages, interpretation of $\mathrm{IHC}$ results, antibodies used for $\mathrm{IHC}[8]$ and storage duration of paraffin blocks. For proper HER2 IHC testing in gastric biopsy samples, it is recommended to have at least four pinch biopsy tissue fragments containing cancer cells [9] and surgical specimens from patients that previously obtained HER2negative results in biopsies should also be tested to increase the chance of finding HER2-positive tumors [10]. To overcome
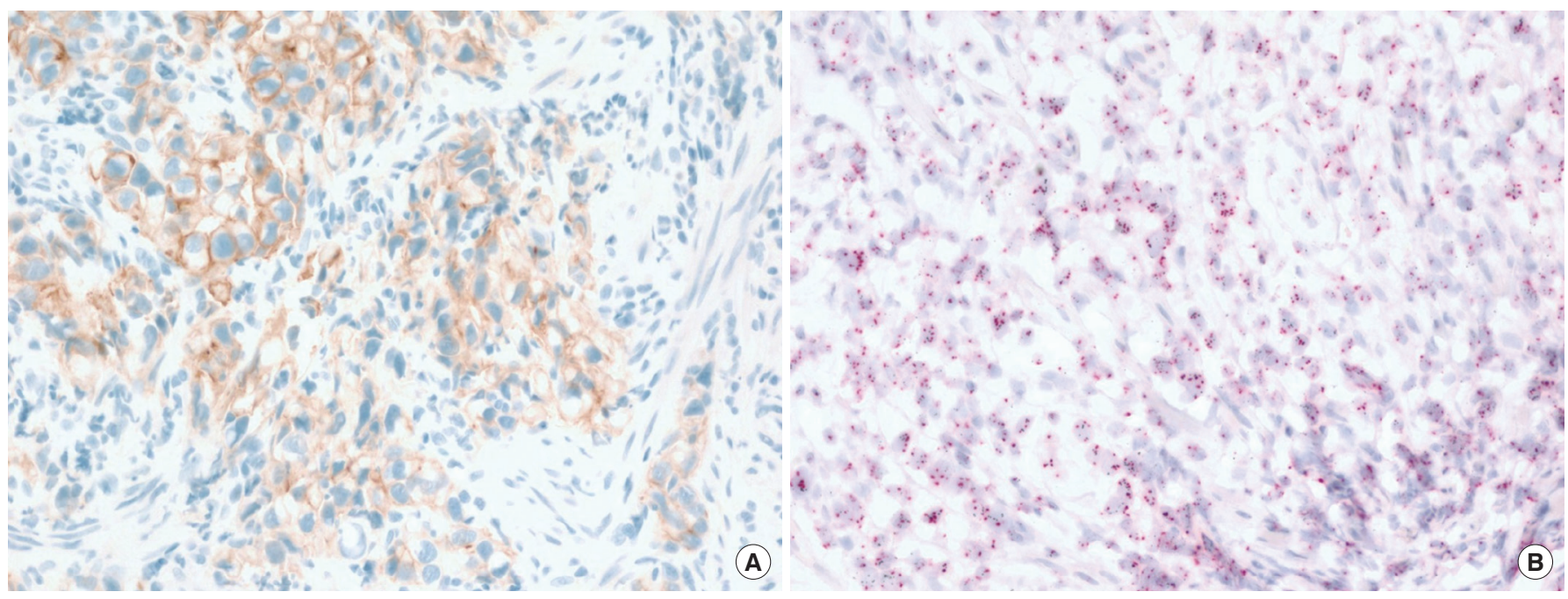

Fig. 1. HER2 (human epidermal growth factor receptor 2) 2+ with chromosome 17 polysomy. (A) Immunohistochemistry finding showing 2+ stained in the membrane of tumor cells. (B) Silver in situ hybridization with chromosome 17 polysomy $(\times 40)$. 
factors affecting gastric HER2 positivity, we should aware the importance of quality assurance and quality control of HER2 testing including careful interpretation, use tissues with more carcinoma cells for biopsy specimen ( $\geq 4$ cancer tissue fragments), selection of intestinal histology in operation specimen, and test both biopsy/surgical specimens and both primary/metastatic specimens.

Genomic alterations associated with HER2-positive GC In patients with HER2-positive GC, tumor protein p53 (TP53) mutation is the most frequent genetic alterations followed by cyclin-dependent kinase Inhibitor 2A (CDKN2A, 4\%), and phosphatidylinositol-4,5-bisphosphate 3-kinase, catalytic subunit a (PIK3CA) and Kirsten rat sarcoma viral oncogene homolong (KRAS) mutations (2\%) [11], and five genes were concomitantly co-amplified: G1/S-specific cyclin-E1 (CCNE1, $8 \%)$, PIK3CA (8\%), KRAS (2\%), cyclin-dependent kinase 4 (CDK4, 2\%), and CDK6 (2\%). These results are consistent with our previous molecular classification study using $300 \mathrm{GC}$ samples, TP53 pathway inactive subgroup was characterized by TP53 loss through deleterious mutations in TP53 or MDM2 (mouse double minute 2 homolog) amplification and characterized by both focal amplifications in oncogenes such as HER2 (17.4\%), epidermal growth factor receptor (EGFR, 7.0\%), MET (3.5\%), and CCNE1 (17.5\%) as well as large scale chromosomal gains and losses. However, HER2-positive GC with concomitant MET and/or EGFR overexpression can be demonstrated in small subsets of GC associated with aggressive behavior [12]. Moreover, all patients with concomitant CCNE1 amplification and HER2 amplification progressed shortly after trastuzumab-based chemotherapy [11]. Hence, in this subset of patients, combination therapy should be tested in the context of clinical trials.

\section{MET (MET PROTO-ONCOGENE, RECEP- TOR TYROSINE KINASE)}

\section{How to select MET-amplified GC using IHC: a new interpretation method}

The establishment of selection criteria in identifying subpopulations that may benefit from treatment is a key aspect of further development of anti-MET monoclonal antibody (MET$\mathrm{Mab}$ ) and hepatocyte growth factor/scatter factor monoclonal antibody treatment [13]. The study with MetMAb in nonsmall cell lung cancer and the study with AMG102 in GC highlight an essential requirement for patient stratification to ensure clinical benefit: high MET expression in cancer cells [14]. In that study, MET overexpression assessed by new interpretation method based on membranous and cytoplasmic staining correlated well with increased copy number gain, mRNA levels and MET gene amplification, and was an independent prognosticator of poor survival, supporting the clinical impact of MET proto-oncogene activation in GC.

\section{MET overexpression caused by MET exon 14 deletion}

The discordance between low MET amplification and high MET protein expression indicates there are other potential mechanisms that can lead to MET overexpression. MET exon
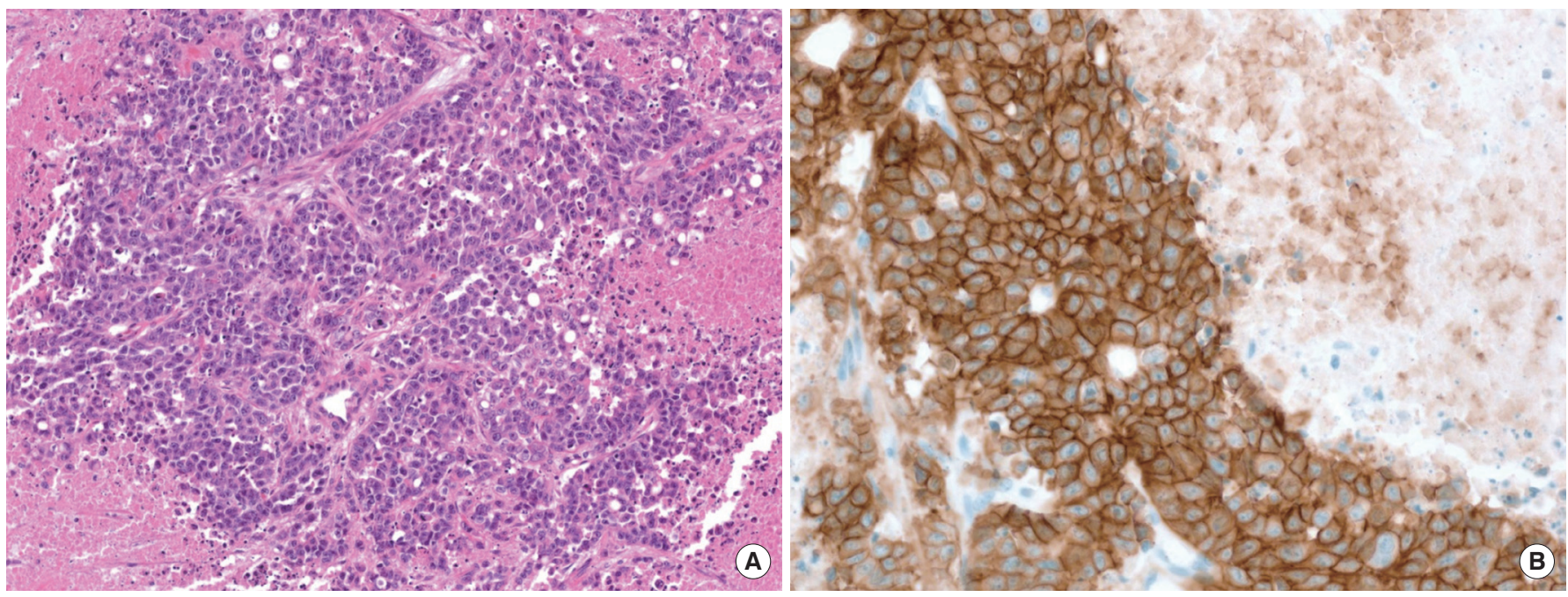

Fig. 2. Mesenchymal-epithelial transition (MET) immunohistochemistry in a gastric cancer case with METex14del (MET exon 14 deletion). H\&E photomicrograph of gastric carcinoma (A) with MET immunohistochemistry showing both membranous and cytoplasmic strong $(3+)$ staining (B) $(\times 40)$. 
14 deletion (METex14del) has been postulated to be one potential mechanism for MET protein overexpression (Fig. 2) [15]. In our previous screening with nCounter fusion transcript analysis with mRNA, we found three GC cases with poorly differentiated adenocarcinoma, METex14 and MET IHC 3+ in both membranous and cytoplasmic staining, in which concomitant MET gene amplification was observed in one case (a 27-year-old male patient with massive malignant ascites and died shortly after diagnosis). His tumor showed strong MET overexpression by IHC (3+) without MET amplification. A selective small molecule inhibitor of Met (PHA665752) and cabozantinib demonstrated potent growth inhibition in METex14del+ patient-derived GC tumor cell line [15].

\section{FGFR2}

\section{FGFR2 in gastric cancer: how can we detect?}

FGFR2 gene amplification, and resulting FGFR2 protein overexpression, is rare in GC patients, and development of an accurate and widely available method for mass screening to identify patients who may respond to treatment with FGFR inhibitors is important. Recently, we found FGFR2 IHC results correlated very well with those of copy number variation [16]. Interestingly, FGFR2 amplification by fluorescence in situ hybridization was observed in $100 \%$ of the IHC $\geq 1+$ cases. Given that several FGFR inhibitors are now in under clinical trials for treatment of metastatic or unresectable GC harboring FGFR2 amplification or FGFR2b overexpression, IHC can be a powerful tool for massive screening of this small subset of GC patients.

\section{Clinical significance of FGFR2}

FGFR2 overexpression is more frequently observed in metastatic lymph nodes compared to matched primary GC. Intriguingly, analysis of paired primary and metastatic GC tumors revealed more FGFR2-positive tumor cells in metastases than in primary GC. We also observed frequent FGFR2 overexpression within lymphatic tumor emboli, which was noteworthy (Fig. 3). Based on marked intratumoral heterogeneity, frequent focal overexpression/amplification of FGFR2 within lymphatic tumor emboli, and preclinical studies, FGFR2 amplification may play important roles in tumor progression, particularly in lymphangitic metastasis of GC, and the potential therapeutic effect from targeted therapy can be expected in patients with this GC subset [16].

\section{RNF43}

\section{Clinical significance of RNF43}

Ubiquitin E3 ligase RNF43 is a transmembrane E3 ubiquitin ligase that potently inhibits Wnt signaling through targeting Wnt receptor for degradation and has been suggested as a negative regulator of Wnt signaling and found to be frequently mutated in many cancers including GC $[17,18]$. Several agents, including porcupine inhibitor, frizzled antibody, and LRP6 (low-density lipoprotein receptor-related protein 6) antibody, are being developed to inhibit ligand-induced Wnt/B-catenin signaling. Previous preclinical observation that all pancreatic cancer cell lines showing strong Wnt dependency carry RNF43 mutations (homozygous mutations of RNF43, F69C, and M18fs) suggests that the presence of RNF43 mutations may serve as
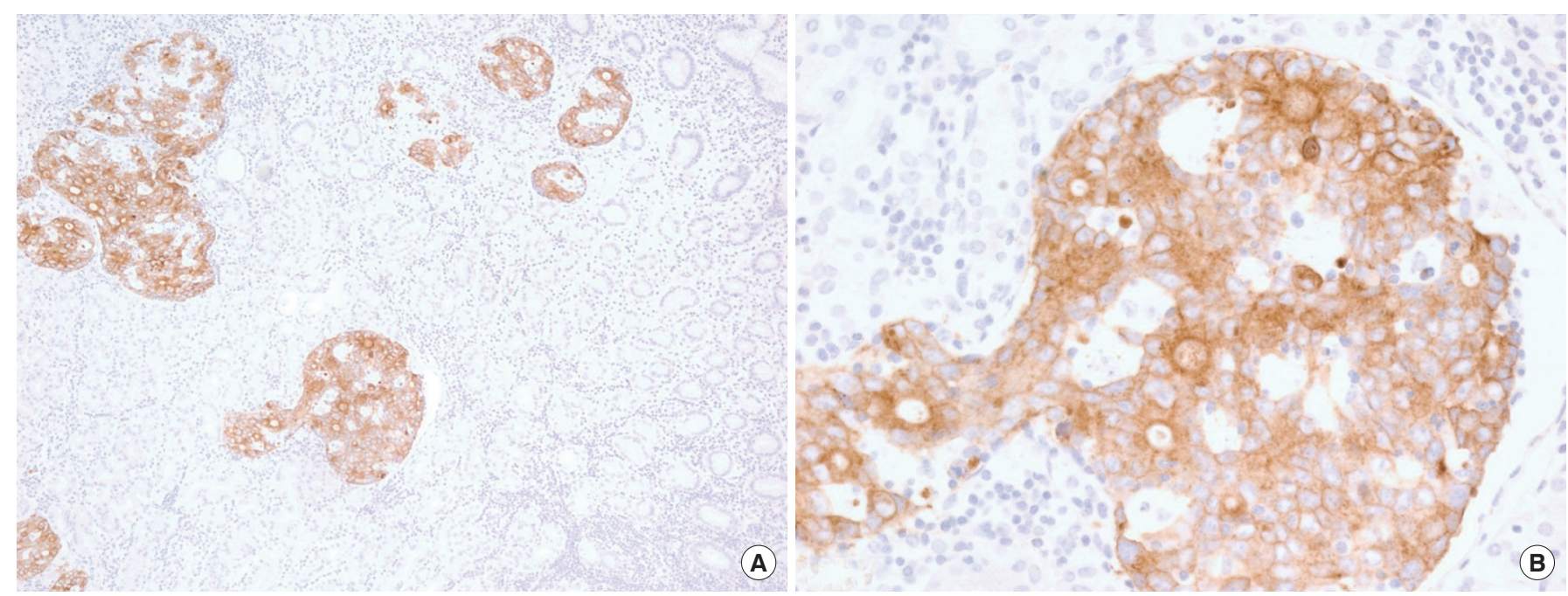

Fig. 3. FGFR2 (fibroblast growth factor receptor 2 ) 3+ stained within lymphatic tumor emboli (A) with lower magnification ( $\times 10)$ and $(B)$ higher magnification showing carcinoma within lymphatic spaces $(\times 40)$. 
a predictive biomarker for selecting patients likely to respond to upstream Wnt pathway inhibitors [19]. However, as the preclinical studies were performed in pancreatic cancers, further studies in GC are needed to validate this conjecture [17].

\section{Prevalence of RNF43 mutations in GC}

Previous two studies on $\mathrm{GC}$ reported that mutation rate of RNF43 was higher in MSI subtype than that of microsatellitestable (MSS) subtype [20,21]. Precisely, RNF43 was mutated in $4.8 \%$ of MSS and $54.6 \%$ of MSI tumors. Among them, $62.5 \%$ of mutations were truncating, and only four MSS GC samples (4.4\%) harbored missense mutations of RNF43. In The Cancer Genome Atlas (TCGA) data, RNF43 was mutated in six out of 215 MSS GC samples, consisting four frameshift and two nonsense mutations. Unexpectedly, four RNF43 mutations were from genomically stable subtype [21]. These observations suggest that truncating mutations of RNF43 in MSS GC would be a good candidate biomarker for therapeutic agents specifically targeting the $W n t / \beta$-catenin signaling.

\section{MSI AND MMR DEFICIENCY}

\section{Clinical significance of MSI and MMR}

TCGA and Samsung Medical Center-Asian Cancer Research Group (SMC-ACRG) GC studies proposed a molecular classification dividing GC into four subtypes and MSI-GC is one of them. MSI is associated with elevated mutation rates, including mutations of genes encoding targetable oncogenic signaling proteins [21]. The incidence of MSI GC was previously reported to be $8.5 \%$ to $37.8 \%$ [22]. MSI-GC is exclusive with EBV-positive GC and more frequent in antral locations (distal stomach), intestinal type be Lauren, female, older ages, and earlier disease stages than tumors within body/cardia, diffuse histology, male, younger patients, and advanced stages $[23,24]$.

\section{Prognosis of MSI-GC}

The prognostic significance of MSI in GC has been controversial [25]. In the previous largest cohort study with consecutive 1,990 GC patients who had undergone curative gastrectomy, the disease-free survival curves showed no significant differences between MSS and MSI patients at each stage of I, II, III, and IV. However, given the detection of MSI in lower disease stages, direct comparison with all MSS-GC would result in better survival [23,26-28]. This lower disease stage and better prognosis would be related with increased TIL found in this subtype. However, as MSI is also detected even in a higher disease stage, in that case, the prognostic significance disappears. Overall, the prognostic significance of MSI would depend on disease stage or sample cohort characteristics rather than MSI itself.

\section{Underlying MMR deficiencies in MSI-GC}

In MSI-GC, in $>90 \%$ of cases are associated with MutL homo$\log 1$ (MLH1) and/or PMS2 losses and are associated with hypermethylation of hMLH1 gene. This type of MSI occurs early during gastric multistep carcinogenesis through adenomacarcinoma found in $30 \%$ of cases $[29,30]$. These observations

Table 1. MMR protein alterations in sporadic MSI-GC cases

\begin{tabular}{|c|c|c|c|c|c|c|c|}
\hline Study & $\begin{array}{l}\text { Total } \\
\text { cases }\end{array}$ & MSI test markers & $\begin{array}{l}\text { No. of MSI- } \\
\text { GC cases (\%) }\end{array}$ & $\begin{array}{l}\text { MLH1 loss } \\
(\%)\end{array}$ & $\begin{array}{l}\text { PMS2 loss } \\
\text { (\%) }\end{array}$ & $\begin{array}{l}\text { MSH2 loss } \\
(\%)\end{array}$ & $\begin{array}{l}\text { MSH6 loss } \\
(\%)\end{array}$ \\
\hline Halling et al. (1999) [31] & 117 & $\begin{array}{l}32 \text { Microsatellite markers including } \\
\text { BAT-26, BAT-25, TGF- } \beta \text { RII }\end{array}$ & $19(16)$ & $\begin{array}{c}5 / 8 \\
\text { Tested (63) }\end{array}$ & ND & $\begin{array}{c}3 / 8 \\
\text { Tested (37) }\end{array}$ & ND \\
\hline Lee et al. (2002) [27] & 327 & BAT-26 & $31(9.5)$ & $24(77)$ & ND & $4(13)$ & ND \\
\hline Leite et al. (2011) [32] & 381 & BAT-25, BAT-26, NR-21, NR-24, NR-27 & $88(23)$ & $\begin{array}{c}18 / 20 \\
\text { Tested (90) }\end{array}$ & $\begin{array}{c}19 / 20 \\
\text { Tested (95) }\end{array}$ & ND & ND \\
\hline Lee et al. (2000) [29] & 156 & $\mathrm{MLH} 1, \mathrm{MSH} 2, \mathrm{IHC}$ & $17(10.9)$ & $17(10.9)$ & ND & 0 & ND \\
\hline Bae et al. (2015) [26] & 2,959 & $\begin{array}{l}\text { BAT25, BAT26, D2S123, D5S346, } \\
\text { D17S250 }\end{array}$ & $203(6.8)$ & $179(88)$ & ND & $15(7.4)$ & ND \\
\hline Cristescu et al..) (2015) [23] & 300 & BAT-25, BAT-26, NR-21, NR-24, NR-27 & $68(22.7)$ & $62(91)$ & ND & $6(9)$ & ND \\
\hline Mathiak et al. (2017) [33] & 452 & BAT-25, BAT-26, NR-21, NR-24, NR-27 & $34(7.5)$ & $30(88)$ & $30(88)$ & $3(9)$ & $3(9)$ \\
\hline
\end{tabular}

MMR, mismatch repair; MSI-GC, microsatellite instability-gastric cancer; MLH1, MutL homolog 1; PMS, postmeiotic segregation; MSH, MutS protein homolog; BAT, big adenine tract; TGF- $\beta R$ III, transforming growth factor $\beta$ receptor II; ND, not done; IHC, immunohistochemistry.

${ }^{\text {a) }}$ This results have not been precisely described in the manuscript. 
explain the frequent occurrence of frequent MSI in older patients with distal gastric location, intestinal histology and earlier disease stage, and finally a favorable prognosis. In less than $10 \%$ of cases with MSI-GC, MutS protein homolog 2 (MSH2), and/or MSH6 losses are found. However, depending on selection of markers for MSI, the frequencies varied from $0 \%$ to $37 \%$ (Table 1 ) $[23,26,27,31-33]$. Given the shortcomings of missing standardized testing algorithms with prevalence of MSI-GC ranging from $0 \%$ to $44.5 \%$ [33] and highly variable MSH2 expression losses, future comprehensive diagnostic algorithm of MSI tests are needed in GC and this is urgently needed because MSI is an important biomarker for immunotherapy, one of the most exciting and new discoveries in recent cancer therapy.

\section{Importance of MSI in a new era of immunotherapy}

Responses to immune checkpoint inhibitors have been observed in tumors with both low and high PD-L1 expression. A strong putative biomarker has emerged in MSI-high status, which results either from germline mutation of DNA MMR genes, as seen in patients with Lynch syndrome, or in tumors with promoter hypermethylation leading to potential gene silencing of DNA MMR pathways.

MSI status results in a higher tumor mutational burden, and patients with MSI colorectal and noncolorectal cancers have shown striking responses to anti-PD-1 therapy in recent trials of pembrolizumab [34]. Whether or not the same is observed in MSI esophagogastric cancers remains to be established (http://www.ascopost.com/issues/june-25-2016/antipd-1-treatment-with-pembrolizumab-in-gastricgastroesophageal-junction-cancers-who-is-likely-to-respond). MSI GCS showed significantly higher rates of PD-L1 expression compared with MSS GCs [35-37]. Genomic profiling has also identified the MSI-GC subtype shows higher expression of the ligands PD-L1 and PD-L2 [21]. Recently we observed frequent overexpression of PD-L1 in MSI-GC in $61.5 \%$ of cases and unexpectedly, we found that PD-L1 expression is independently associated with longer survival even within MSI-GC cases [25].

\section{EBV}

\section{Clinical significance of $\mathrm{EBV}+\mathrm{GC}$}

EBV-positive GC (EBV+GC) is one of the four subtypes of GC, as defined by TCGA having several clinicopathological features such as longer survival and higher frequency of lymphoepithelioma-like carcinoma (LELC) or increased TIL (also known as Crohn-like reaction [CLR]) that distinguish it from EBV-neg- ative GC (EBVnGC). TIL constitute the principal cellular component of the immune-active tumor microenvironment and their presence contributes to improved survival of patients with cancer [38]. The number of TILs increases in EBV+GC, especially in LELC or CLR. The presence of EBV+ tumors negatively correlates with the TNM (tumour, node, and metastasis) stage parameter as well as with the values of its individual components (primary tumor site, regional lymph node involvement, or presence of distant metastasis) [39]. Overall, EBV positivity is associated with favorable prognosis and this survival difference is mainly achieved by a degree of TIL within the microenvironment of cancer [40].

\section{Deregulated immune response and TIL}

Recently, we reported a gene expression profile analysis to compare tumor and non-tumor gastric tissues from 12 patients with $\mathrm{EBV}+\mathrm{GC}$ and found that $\mathrm{EBV}+\mathrm{GC}$ had a higher degree of genetic homogeneity than EBVnGC cases. Deregulation of gene expression affected fewer genes in EBV+GC compared to $E B V n G C$ with significantly altered expression signals especially in cytokine (chemokine) pathways [41]. These changes could recruit reactive immune cells to the intra- or peritumoral area of EBV+GC (can be designated as TIL) and this circumstance might contribute to longer survival of patients with $\mathrm{EBV}+\mathrm{GC}$ compared to $\mathrm{EBVnGC}$ and make $\mathrm{EBV}+\mathrm{GC}$ as a distinct tumor with prominent inflammatory infiltrates. $E B V+G C$ has evidence of hyperactive adaptive and innate immunity, with evidence of T-cell activation via the cytokines interleukin 2 (IL-2), IL-12, IL-23, and IL-27 [21,42].

\section{Biomarkers in EBV+GC}

Several studies found that EBV+GC is often accompanied by more extensive infiltration of CD8-positive cytotoxic T cells, FoxP3+ T regulatory $T$ cells and higher interferon- $\gamma$ expression, which induce the expression of indoleamine 2,3-dioxygenase (IDO1), a potent immune cell inhibitor, in EBV+GC cells $[25,43]$. Recent genomic profiling studies revealed frequent somatic mutations of PIK3CA (10.3\% to $80 \%)$, AT-rich interactive domain-containing protein $1 \mathrm{~A}$ (ARID1A, $47 \%$ to $55 \%)$, v-akt murine thymoma viral oncogene homolog 2 (AKT2, 38.2\%), and B cell lymphoma 6 corepressor (BCOR, $23 \%$ ) genes [44] and amplification of Janus kinase 2 and PDL1/L2 [21]. Recent IHC study in $32 \mathrm{EBV}+\mathrm{GC}$ observed overwhelming PD-L1 staining in tumor cells in $50 \%$ and immune cells in $94 \%$ of cases. Moreover, interferon- $\gamma$ driven gene signature, an additional proposed marker of sensitivity to PD-1 therapy, were also enriched in $\mathrm{EBV}+\mathrm{GC}$ suggesting that pa- 
tients with $E B V+G C$ may have greater likelihood of response to PD-1 blockade [45]. Therefore, in EBV+GC patients, the combination of anti-PD-1/PD-L1 agents and IDO inhibitor would be active areas of further investigation in cases failed to conventional chemotherapy or PIK3CA/AKT/mTOR inhibitor therapies.

\section{PD-L1 AND TIL}

After years of controversy, it is now recognized that the immune system can play a role in the control of tumor growth and progression, a process known as cancer immunoediting [46]. The host immune system can also contributes to the efficacy of some cancer therapies where the tumor death induced may be "immunogenic" [47]. Recently, classification of tumors into four groups on the basis of their PD-L1 status and presence or absence of TILs has already been proposed $[46,48]$. These include type I (PD-L1+ with TILs driving adaptive immune resistance), type II (PD-L1 negative with no TIL indicating immune ignorance), type III (PD-L1+ with no TIL indicating intrinsic induction), and type IV (PD-L1 negative with TIL indicating the role of other suppressors in promoting immune tolerance). The proportions of various human tumors that fit into each of these types, as defined by TILS/ PD-L1 status, likely depends on the genetic aberrations and oncogene drivers of the cancer as well as the tissue they arise in [46]. Although this classifications were well described and validated in melanoma, analogous frequencies in GC generated by the same methodologies are not available. Future comprehensive studies are strongly required in GC. Tailoring cancer immunotherapy based on type of tumor microenvironment is well described in a recent review paper [46].

\section{CONCLUSION}

We reviewed the present and emerging biomarkers in GC. There are efforts to classify GC based on molecular findings with clinical significances $[21,23]$. Based on previous classifications and biomarkers, we revisited new molecular classifications of GC for precision cancer therapy (Table 2). In a new era

Table 2. Four gastric cancer subtypes based on clinical findings and genomic alterations

\begin{tabular}{|c|c|c|c|c|}
\hline Subtype & EBV/TP53 active & MSI & TP53 inactive/CIN & EMT/GS \\
\hline $\begin{array}{l}\text { Characteristic genetic/ } \\
\text { signalling alteration }\end{array}$ & $\begin{array}{l}\text { Frequent PIK3CA mutation } \\
\text { intact TP53 activity }\end{array}$ & MMR gene inactivation & $\begin{array}{l}\text { TP53 functional loss with fre- } \\
\text { quent clonal TP53 mutation } \\
\text { and subclonal mutations of } \\
\text { APC, ARID1A, KRAS, PIK3CA }\end{array}$ & $\begin{array}{l}\text { Infrequent subclonal mu- } \\
\text { tations of genes involved } \\
\text { in cell adhesion (CDH1, } \\
\text { CTNNA1, RhoA) }\end{array}$ \\
\hline Epigenetic alteration & $\begin{array}{l}\text { EBV-CIMP with CDKN2A } \\
\text { silencing }\end{array}$ & $\begin{array}{l}\text { Gastric CIMP with MLH1 } \\
\text { silencing }\end{array}$ & Not characteristic & $\begin{array}{l}\mathrm{CDH} 1 \text { silencing in hereditary } \\
\text { diffuse gastric cancer }\end{array}$ \\
\hline $\begin{array}{l}\text { Genomic level alter- } \\
\text { ations }\end{array}$ & $\begin{array}{l}\text { Deregulation of immune } \\
\text { response genes }\end{array}$ & $\begin{array}{l}\text { Hypermutation with frequent } \\
\text { frameshift mutations }\end{array}$ & $\begin{array}{l}\text { Aneuploid with frequent focal } \\
\text { amplifications }\end{array}$ & $\begin{array}{l}\text { Diploid with rare subclonal } \\
\text { mutations }\end{array}$ \\
\hline $\begin{array}{l}\text { Immune cells infiltra- } \\
\text { tion }\end{array}$ & Increased TILs (due to EBV) & $\begin{array}{l}\text { Increased TILs (due to neoan- } \\
\text { tigens) }\end{array}$ & Variable TILs & Variable TILs \\
\hline Other characteristics & $\begin{array}{l}\text { Upper and mid stomach, } \\
\text { male predominance, } \\
\text { relatively young and earlier } \\
\text { stage }\end{array}$ & $\begin{array}{l}\text { Antral locations, intestinal } \\
\text { type, more female, rela- } \\
\text { tively older age and earlier } \\
\text { stage }\end{array}$ & $\begin{array}{l}\text { More frequent in intestinal or } \\
\text { mixed histology }\end{array}$ & $\begin{array}{l}\text { Diffuse histology with ad- } \\
\text { vanced disease stage and } \\
\text { dismal prognosis }\end{array}$ \\
\hline Biomarker & $\begin{array}{l}\text { PD-L1, mutations of ARID1A } \\
\text { and PIK3CA, TIL, IDO1, } \\
\text { interleukin-2, interferon- } \gamma\end{array}$ & $\begin{array}{l}\text { PD-L1, TIL, interferon- } \gamma \text {, } \\
\text { RNF43 }\end{array}$ & $\begin{array}{l}\text { Amplification/overexpression } \\
\text { of RTKs, KRAS, and PIK3CA }\end{array}$ & $\begin{array}{l}\text { EMT signature with rare can- } \\
\text { cer-driver gene alteration }\end{array}$ \\
\hline $\begin{array}{l}\text { Tumor microenviron- } \\
\text { ment }\end{array}$ & $\begin{array}{l}\text { Type I (PD-L1+ with TILs) } \\
\text { >> II or IV }\end{array}$ & $\begin{array}{l}\text { Type I (PD-L1+ with TILs) } \\
\text { >> II or IV }\end{array}$ & Type II, III, or IV >> I & Type II or IV >> I or III \\
\hline
\end{tabular}

EBV, Epstein-Barr virus; TP53, tumor protein p53; MSI, microsatellite instability; CIN, chromosomal instability; EMT, epithelial mesenchymal transition; GS, genomically stable; PIK3CA, phosphatidylinositol-4,5-bisphosphate 3-kinase, catalytic subunit $\alpha$; MMR, mismatch repair; APC, adenomatous polyposis coli; ARID1A, AT-rich interactive domain-containing protein $1 \mathrm{~A}$; KRAS, Kirsten rat sarcoma viral oncogene homolong; $\mathrm{CDH} 1$, cadherin-1; CTNNA1, a-E-catenin; RhoA, ras homolog gene family, member A; CIMP, CpG-island methylation phenotype; CDKN2A, cyclin-dependent kinase Inhibitor 2A; MLH1, MutL homolog 1; TIL, tumor infiltrating lymphocytes; PD-L1, programmed cell death ligand-1; IDO1, indoleamine 2,3dioxygenase 1; RNF43, ring finger protein 43; RTK, receptor tyrosine kinase. 
of immunotherapy of GC, we urgently need an accurate and sensitive method to detect MSI in GC and classification of GC into four groups by PD-L1 and TIL status to explore mechanisms underlying response or resistance for immunotherapy.

\section{CONFLICTS OF INTEREST}

No potential conflict of interest relevant to this article was reported.

\section{ACKNOWLEDGMENTS}

This work was supported by a grant from the Korean Health Technology R\&D Project, Ministry of Health and Welfare, Republic of Korea (HI14C3418, HI16C1990). Support was also provided by a grant from the 20 by 20 project of Samsung Medical Center (GF01140111).

\section{REFERENCES}

1. Xu W, Yang Z, Lu N. Molecular targeted therapy for the treatment of gastric cancer. J Exp Clin Cancer Res 2016;35:1.

2. Riquelme I, Saavedra K, Espinoza JA, Weber H, Garcia P, Nervi B, et al. Molecular classification of gastric cancer: towards a pathway-driven targeted therapy. Oncotarget 2015;6:24750-79.

3. Wong SS, Kim KM, Ting JC, Yu K, Fu J, Liu S, et al. Genomic landscape and genetic heterogeneity in gastric adenocarcinoma revealed by whole-genome sequencing. Nat Commun 2014;5:5477.

4. Young K, Chau I. Targeted therapies for advanced oesophagogastric cancer: recent progress and future directions. Drugs 2016;76:13-26.

5. Ruschoff J, Hanna W, Bilous M, Hofmann M, Osamura RY, Penault-Llorca $F$, et al. HER2 testing in gastric cancer: a practical approach. Mod Pathol 2012;25:637-50.

6. Cho EY, Park K, Do I, Cho J, Kim J, Lee J, et al. Heterogeneity of ERBB2 in gastric carcinomas: a study of tissue microarray and matched primary and metastatic carcinomas. Mod Pathol 2013;26:677-84.

7. Cho J, Jeong J, Sung J, Sung CO, Kim KM, Park CK, et al. A large cohort of consecutive patients confirmed frequent HER2 positivity in gastric carcinomas with advanced stages. Ann Surg Oncol 2013;20 Suppl 3:S477-84.

8. Cho EY, Srivastava A, Park K, Kim J, Lee MH, Do I, et al. Comparison of four immunohistochemical tests and FISH for measuring HER2 expression in gastric carcinomas. Pa- thology 2012;44:216-20.

9. Ahn S, Ahn S, Van Vrancken M, Lee M, Ha SY, Lee H, et al. Ideal number of biopsy tumor fragments for predicting HER2 status in gastric carcinoma resection specimens. Oncotarget 2015;6:38372-80.

10. Park SR, Park YS, Ryu MH, Ryoo BY, Woo CG, Jung HY, et al. Extra-gain of HER2-positive cases through HER2 reassessment in primary and metastatic sites in advanced gastric cancer with initially HER2-negative primary tumours: Results of GASTric cancer HER2 reassessment study 1 (GASTHER1). Eur J Cancer 2016;53:42-50.

11. Lee JY, Hong M, Kim ST, Park SH, Kang WK, Kim KM, et al. The impact of concomitant genomic alterations on treatment outcome for trastuzumab therapy in HER2-positive gastric cancer. Sci Rep 2015;5:9289.

12. Ha SY, Lee J, Jang J, Hong JY, Do IG, Park SH, et al. HER2positive gastric cancer with concomitant MET and/or EGFR overexpression: a distinct subset of patients for dual inhibition therapy. Int J Cancer 2015;136:1629-35.

13. Spigel DR, Ervin TJ, Ramlau R, Daniel DB, Goldschmidt $\mathrm{JH}$, Blumenschein $\mathrm{GR}$, et al. Final efficacy results from OAM4558g, a randomized phase II study evaluating MetMAb or placebo in combination with erlotinib in advanced NSCLC. J Clin Oncol 2011;29(15 Suppl):7505.

14. Ha SY, Lee J, Kang SY, Do IG, Ahn S, Park JO, et al. MET overexpression assessed by new interpretation method predicts gene amplification and poor survival in advanced gastric carcinomas. Mod Pathol 2013;26:1632-41.

15. Lee J, Ou SH, Lee JM, Kim HC, Hong M, Kim SY, et al. Gastrointestinal malignancies harbor actionable MET exon 14 deletions. Oncotarget 2015;6:28211-22.

16. Ahn S, Lee J, Hong M, Kim ST, Park SH, Choi MG, et al. FGFR2 in gastric cancer: protein overexpression predicts gene amplification and high $\mathrm{H}$-index predicts poor survival. Mod Pathol 2016;29:1095-103.

17. Lin Y, Wu Z, Guo W, Li J. Gene mutations in gastric cancer: a review of recent next-generation sequencing studies. Tumour Biol 2015;36:7385-94.

18. Giannakis M, Hodis E, Jasmine Mu X, Yamauchi M, Rosenbluh J, Cibulskis K, et al. RNF43 is frequently mutated in colorectal and endometrial cancers. Nat Genet 2014;46: 1264-6.

19. Jiang X, Hao HX, Growney JD, Woolfenden S, Bottiglio C, $\mathrm{Ng} \mathrm{N}$, et al. Inactivating mutations of RNF43 confer Wnt dependency in pancreatic ductal adenocarcinoma. Proc Natl Acad Sci U S A 2013;110:12649-54.

20. Wang K, Yuen ST, Xu J, Lee SP, Yan HH, Shi ST, et al. Whole- 
genome sequencing and comprehensive molecular profiling identify new driver mutations in gastric cancer. Nat Genet 2014;46:573-82.

21. Cancer Genome Atlas Research Network. Comprehensive molecular characterization of gastric adenocarcinoma. Nature 2014;513:202-9.

22. Choi YY, Bae JM, An JY, Kwon IG, Cho I, Shin HB, et al. Is microsatellite instability a prognostic marker in gastric cancer? A systematic review with meta-analysis. J Surg Oncol 2014;110:129-35.

23. Cristescu R, Lee J, Nebozhyn M, Kim KM, Ting JC, Wong $\mathrm{SS}$, et al. Molecular analysis of gastric cancer identifies subtypes associated with distinct clinical outcomes. Nat Med 2015;21:449-56.

24. An JY, Kim H, Cheong JH, Hyung WJ, Kim H, Noh SH. Microsatellite instability in sporadic gastric cancer: its prognostic role and guidance for 5-FU based chemotherapy after R0 resection. Int J Cancer 2012;131:505-11.

25. Cho J, Lee J, Bang H, Kim ST, Park SH, An JY, et al. Programmed cell death-ligand 1 expression predicts survival in patients with gastric carcinoma with microsatellite instability. Oncotarget 2017;8:13320-8.

26. Bae YS, Kim H, Noh SH, Kim H. Usefulness of immunohistochemistry for microsatellite instability screening in gastric cancer. Gut Liver 2015;9:629-35.

27. Lee HS, Choi SI, Lee HK, Kim HS, Yang HK, Kang GH, et al. Distinct clinical features and outcomes of gastric cancers with microsatellite instability. Mod Pathol 2002;15:632-40.

28. Lee HJ, Jang YJ, Lee EJ, Kim JH, Park SS, Park SH, et al. The significance of mismatch repair genes in gastric cancer. J Cancer Res Ther 2013;9:80-3.

29. Kim HS, Woo DK, Bae SI, Kim YI, Kim WH. Microsatellite instability in the adenoma-carcinoma sequence of the stomach. Lab Invest 2000;80:57-64.

30. Min BH, Hwang J, Kim NK, Park G, Kang SY, Ahn S, et al. Dysregulated Wnt signalling and recurrent mutations of the tumour suppressor RNF43 in early gastric carcinogenesis. J Pathol 2016;240:304-14.

31. Halling KC, Harper J, Moskaluk CA, Thibodeau SN, Petroni GR, Yustein AS, et al. Origin of microsatellite instability in gastric cancer. Am J Pathol 1999;155:205-11.

32. Leite M, Corso G, Sousa S, Milanezi F, Afonso LP, Henrique $\mathrm{R}$, et al. MSI phenotype and MMR alterations in familial and sporadic gastric cancer. Int J Cancer 2011;128:160613.

33. Mathiak M, Warneke VS, Behrens HM, Haag J, Boger C, Kruger $\mathrm{S}$, et al. Clinicopathologic characteristics of microsat- ellite instable gastric carcinomas revisited: urgent need for standardization. Appl Immunohistochem Mol Morphol 2017;25:12-24.

34. Le DT, Uram JN, Wang H, Bartlett BR, Kemberling H, Eyring $A D$, et al. $P D-1$ blockade in tumors with mismatch-repair deficiency. N Engl J Med 2015;372:2509-20.

35. Ma C, Patel K, Singhi AD, Ren B, Zhu B, Shaikh F, et al. Programmed death-ligand 1 expression is common in gastric cancer associated with Epstein-Barr virus or microsatellite instability. Am J Surg Pathol 2016;40:1496-506.

36. Lin SJ, Gagnon-Bartsch JA, Tan IB, Earle S, Ruff L, Pettinger $\mathrm{K}$, et al. Signatures of tumour immunity distinguish Asian and non-Asian gastric adenocarcinomas. Gut 2015;64: 1721-31.

37. Boger C, Behrens HM, Mathiak M, Kruger S, Kalthoff H, Rocken C. PD-L1 is an independent prognostic predictor in gastric cancer of Western patients. Oncotarget 2016; 24269-83.

38. Cho J, Kang MS, Kim KM. Epstein-Barr virus-associated gastric carcinoma and specific features of the accompanying immune response. J Gastric Cancer 2016;16:1-7.

39. Camargo MC, Kim WH, Chiaravalli AM, Kim KM, Corvalan $\mathrm{AH}$, Matsuo K, et al. Improved survival of gastric cancer with tumour Epstein-Barr virus positivity: an international pooled analysis. Gut 2014;63:236-43.

40. Song HJ, Srivastava A, Lee J, Kim YS, Kim KM, Ki Kang W, et al. Host inflammatory response predicts survival of patients with Epstein-Barr virus-associated gastric carcinoma. Gastroenterology 2010;139:84-92.e2.

41. Kim SY, Park C, Kim HJ, Park J, Hwang J, Kim JI, et al. Deregulation of immune response genes in patients with Epstein-Barr virus-associated gastric cancer and outcomes. Gastroenterology 2015;148:137-47.e9.

42. Gulley ML. Genomic assays for Epstein-Barr virus-positive gastric adenocarcinoma. Exp Mol Med 2015;47:e134.

43. Choi HS, Ha SY, Kim HM, Ahn SM, Kang MS, Kim KM, et al. The prognostic effects of tumor infiltrating regulatory $T$ cells and myeloid derived suppressor cells assessed by multicolor flow cytometry in gastric cancer patients. Oncotarget 2016;7:7940-51.

44. Shinozaki-Ushiku A, Kunita A, Fukayama M. Update on Epstein-Barr virus and gastric cancer (review). Int J Oncol 2015;46:1421-34.

45. Derks S, Liao X, Chiaravalli AM, Xu X, Camargo MC, Solcia E, et al. Abundant PD-L1 expression in Epstein-Barr virus-infected gastric cancers. Oncotarget 2016;7:32925-32.

46. Teng MW, Ngiow SF, Ribas A, Smyth MJ. Classifying cancers 
based on T-cell infiltration and PD-L1. Cancer Res 2015; 75:2139-45.

47. Kroemer G, Galluzzi L, Kepp O, Zitvogel L. Immunogenic cell death in cancer therapy. Annu Rev Immunol 2013;31: 51-72.
48. Taube JM, Anders RA, Young GD, Xu H, Sharma R, McMiller TL, et al. Colocalization of inflammatory response with B7-h1 expression in human melanocytic lesions supports an adaptive resistance mechanism of immune escape. Sci Transl Med 2012;4:127ra37. 